\title{
Ishige okamurae reduces blood glucose levels in high-fat diet mice and improves glucose metabolism in the skeletal muscle and pancreas
}

Hye-Won Yang ${ }^{1 \dagger}$, Myeongjoo Son ${ }^{2,3+}$, Junwon Choi ${ }^{2,3}$, Seyeon Oh ${ }^{3}$, You-Jin Jeon ${ }^{1,4}$, Kyunghee Byun ${ }^{2,3^{*}}$ and Bo Mi Ryu ${ }^{1,4^{*}}$

\begin{abstract}
Brown alga (Ishige okamurae; IO) dietary supplements have been reported to possess anti-diabetic properties. However, the effects of $\mathrm{IO}$ supplements have not been evaluated on glucose metabolism in the pancreas and skeletal muscle. C57BL/6 N male mice (age, 7 weeks) were arranged in five groups: a chow diet with 0.9\% saline (NFD/saline group), high-fat diet (HFD) with $0.9 \%$ saline (HFD/saline group). high-fat diet with $25 \mathrm{mg} / \mathrm{kg} 1 \mathrm{O}$ extract (HFD/25/IOE). high-fat diet with $50 \mathrm{mg} / \mathrm{kg} 1 \mathrm{O}$ extract (HFD/50/IOE), and high-fat diet with $75 \mathrm{mg} / \mathrm{kg} / \mathrm{O}$ extract (HFD/ 75/IOE). After 4 weeks, the plasma, pancreas, and skeletal muscle samples were collected for biochemical analyses. IOE significantly ameliorated glucose tolerance impairment and fasting and $2 \mathrm{~h}$ blood glucose level in HFD mice. IOE also stimulated the protein expressions of the glucose transporters (GLUTs) including GLUT2 and GLUT4 and those of their related transcription factors in the pancreases and skeletal muscles of HFD mice, enhanced glucose metabolism, and regulated blood glucose level. Our results suggest Ishige okamurae extract may reduce blood glucose levels by improving glucose metabolism in the pancreas and skeletal muscle in HFD-induced diabetes.
\end{abstract}

Keywords: Ishige okamurae, Diabetes, High-fat diet mice, Skeletal muscle, Pancreas

\section{Background}

Type 2 diabetes is the complex metabolic disorders characterized by an abnormal glucose metabolism arising from pancreatic $\beta$-cell dysfunction and glucose intolerance (Hamza et al. 2010, Guilherme et al. 2008, Bell et al. 2001). Glucose metabolism is an essential target to treat type 2 diabetes (Rines et al. 2016, Tsuneki et al. 2004). Controlling blood glucose levels requires the establishment of balance between glucose utilization,

\footnotetext{
* Correspondence: khbyun1@gachon.ac.kr; bmryu@jejunu.ac.kr

${ }^{\dagger}$ Hye-Won Yang and Myeongjoo Son contributed equally to this work.

${ }^{2}$ Department of Anatomy \& Cell Biology, Gachon University College of Medicine, Incheon 21565, Republic of Korea

'Department of Marine Life Science, School of Marine Biomedical Sciences, Jeju National University, 1 Ara 1-dong, Jejudaehak-ro, Jeju 63243, Republic of Korea

Full list of author information is available at the end of the article
}

glucose production, and glucose transport (Giugliano et al. 2008). Previous studies have emphasized adults in a state of glucose intolerance and obesity of children and adolescents are at increased risk of disrupted glucose metabolism (Wiegand et al. 2005). Furthermore, it has been established glucose intolerance and $\beta$-cell dysfunction are characteristics of the pathogenesis of impaired glucose metabolism. Hyperglycemia and glucose intolerance are suppressed by improved glucose transport, which is regulated by the GLUT transporter family (e.g., GLUT2 and GLUT4), and members of this family are essential for the controlling blood glucose level (Nishiumi et al. 2010, Yamashita et al. 2012). Herman and Kahn reported glucose transport occurs in the pancreatic $\beta$-cells, skeletal muscle, adipose tissue, and brain and that it is

(c) The Author(s). 2020 Open Access This article is licensed under a Creative Commons Attribution 4.0 International License, which permits use, sharing, adaptation, distribution and reproduction in any medium or format, as long as you give

appropriate credit to the original author(s) and the source, provide a link to the Creative Commons licence, and indicate if changes were made. The images or other third party material in this article are included in the article's Creative Commons licence, unless indicated otherwise in a credit line to the material. If material is not included in the article's Creative Commons licence and your intended use is not permitted by statutory regulation or exceeds the permitted use, you will need to obtain permission directly from the copyright holder. To view a copy of this licence, visit http://creativecommons.org/licenses/by/4.0/ 
essentially required for blood glucose homeostasis (Herman et al. 2006).

The glucose transporter 2 (GLUT2) in pancreatic $\beta$ cells is demanded for glucose-stimulated glucose tolerance and insulin secretion, which are both reduced in diabetic mouse models (Bonny et al. 1997). On the other hand, glucose transporter 4 (GLUT4) in the skeletal muscle is a key glucose transporter and plays an essential role in the extracellular glucose transport into insulin-sensitive cells (Chang et al. 2004, Shan et al. 2011).

Seaweeds are valuable sources containing diverse bioactive substances with potentials as nutraceutical and pharmaceutical agents (Lee et al. 2010, Kiuru et al. 2014), and recent studies have reported seaweeds and their active substances can improve glucose metabolism by stimulating glucose transport in diabetes (Murugan et al. 2015, Sharifuddin et al. 2015). Ishige okamurae (IO), as an edible brown seaweed, has been shown to contain biologically active substances like diphlorethohydroxycarmalol (DPHC), ishophloroglucin A, and fucoxanthin and associated secondary metabolites (Sanjeewa et al. 2017). Furthermore, it was shown in a previous study that an ethanolic IO extract (IOE) regulated blood glucose level by increasing the level of glucosemetabolizing enzyme in the liver and promoting insulin resistance in $\mathrm{db} / \mathrm{db}$ mice which is a leptin receptordeficient model (Min et al. 2011). However, the effect of IOE has not been investigated on the glucose metabolism in the pancreas and muscle of high-fat diet (HFD)fed mice (a well-established model of glucose intolerance) (Honors et al. 2012, Riant et al. 2009). Accordingly, we evaluated the effects of an IOE on the protein levels of glucose GLUT2 and GLUT4 and on those of linked transcription factors of the pancreas and skeletal muscle and on blood glucose levels in HFD mice.

\section{Materials and methods \\ Extraction of Ishige okamurae}

The $50 \%$ of ethanol extract of Ishige okamurae (IOE) was supplied by Shinwoo Co. Ltd. (Lot No. SW9E29SA, Republic of Korea) as previously described by Yang et al. (2019). Depending on a previous method (Ryu et al. 2018), the IOE used to this study was standardized by assuming diphlorethohydroxycarmalol (DPHC, 2.37\%) via HPLC analysis. The HPLC chromatogram of DPHC is shown in Figure A1. The chromatographic analyses were carried out by an Alliance 2695 Separations Module equipped with a 2998 PDA detector (all from Waters, Milford, MA, USA) and an Agilent poroshell 120 EC-C18 column $(4.6 \times 100 \mathrm{~mm}, 4 \mu \mathrm{m})$. And, the mobile phase contained (A) $0.1 \%$ formic acid in water and (B) $\mathrm{ACN}$ with $0.1 \%$ formic acid. The eluting conditions of HPLC were as follows: $20-40 \%$ B for $25 \mathrm{~min}$, following that re-equilibration time of the column for 10 mins. The rate of flow was kept at $0.3 \mathrm{~mL} / \mathrm{min}$ and the injection volume was $10 \mu \mathrm{L}$. The content of DPHC was validated at Korea Health Supplement Institute (KHSI; Seongnam-si, Gyeonggi-do, Republic of Korea). The presence of DPHC was inspected by quadrupole timeof-flight lipid chromatography-mass spectrometry (QTOF LC-MS/MS) using an electrospray ionization (ESI) source (maXis-HD, Bruker Daltonics, Breman, Germany) at the Korea Basic Science Institute (KBSI; Ochang, South Korea).

\section{High-fat diet-fed mouse}

C57BL/6N male mouse (age, 7 weeks) was purchased from Orient Bio Inc. (Republic of Korea) and housed individually in stainless steel cages at $24^{\circ} \mathrm{C}$ and $45-50 \%$ $\mathrm{RH}$ with a 12-h light-dark cycle. Before the experimental period, all mice were fed a control chow diet for 1 week. All mice were randomly allocated to five groups $(n=3$ for each group): mice were fed a chow diet for 8 weeks with $0.9 \%$ saline (wt/wt on chow diet) for the last 4 weeks (the NFD/saline group); mice were fed a $45 \%$ high-fat diet (HFD) (Research Diet Inc., USA) for 8 weeks with $0.9 \%$ saline (wt/wt on HFD) for the last 4 weeks (the HFD/saline group); and mice were fed the $45 \%$ HFD for 8 weeks with $25 \mathrm{mg} / \mathrm{kg}$ (HFD/25 IOE), 50 $\mathrm{mg} / \mathrm{kg}$ (HFD/50 IOE), or $75 \mathrm{mg} / \mathrm{kg}$ (HFD/75/IOE) of IOE during the latter 4 weeks. Mice were sacrificed on experimental day 57 in accordance with guidelines signed by the Animal Care and Use Committee of Gachon University (IACUC; LCDI-2018-0112).

\section{Glucose tolerance testing (IPGTT)}

The intraperitoneal injection of glucose $(2 \mathrm{~g} / \mathrm{kg}$ of body weight) in mice that had been fasted for $8 \mathrm{~h}$ and blood was obtained from a tail vein 30,60, 90, or $120 \mathrm{~min}$ later, as previously described (Konrad et al. 2002). Serum glucose level was measured using a blood glucose meter (AccuChek Advantage; Roche Diagnostics Corp., USA).

\section{Immunohistochemistry}

Paraffin blocks of pancreatic tissue were sectioned at $5 \mu \mathrm{m}$, laid on coating slides, dried at $40^{\circ} \mathrm{C}$ for $12 \mathrm{~h}$, and deparaffinized using xylene. And then, the deparaffinized tissue sections were incubated in $0.3 \%$ hydrogen peroxide (Sigma-Aldrich, USA) for $30 \mathrm{~min}$, washed 3 times with PBS (phosphate-buffered saline), blocked with normal animal serum, incubated with anti-PCNA antibody (Abcam, USA), and rinsed with PBS 3 times. The tissue sections were incubated with biotinylated secondary antibodies in the $A B C$ kit (Vector Laboratories, USA), washed 3 times with PBS, treated with $\mathrm{DAB}$ (3, 3diaminobenzidine) substrate to $0.03 \%$ hydrogen peroxide for $10 \mathrm{~min}$, mounted using a xylene-based DPX 
mounting solution (Sigma-Aldrich, USA), and photographed under the microscope (Olympus Optical Co., Japan).

\section{Immunofluorescence}

The pancreas and skeletal muscle (soleus and gastrocnemius muscle) paraffin block section $(5 \mu \mathrm{m})$ was deparaffinized, treated with animal serums for blocking antibody binding, and incubated with anti-GLUT2 and anti-GLUT4 antibodies (Santa Cruz Biotechnology, Inc., USA) at $4{ }^{\circ} \mathrm{C}$ for 1 day. And then, the tissue sections were washed with PBS, incubated with fluorescence conjugated secondary antibody at room temperature for $1 \mathrm{~h}$, stained with DAPI (4' 6-diamidino-2-phenylindole; Sigma-Aldrich, USA) solution for $1 \mathrm{~min}$, rinsed with PBS 3 times, and mounted using Vectorshield solution (Vector Laboratories). Fluorescences were detected using confocal microscopy (LSM 700; Carl Zeiss Ltd., Germany).

\section{Quantitative real-time polymerase chain reaction}

Total RNAs of mouse's pancreases and skeletal muscles (soleus and gastrocnemius) were lyzed using the RNAiso Plus kit (TAKARA, Japan). Briefly, cell pellets were suspended using $1000 \mu \mathrm{l}$ RNAiso Plus by pipetting, and lysates were mixed with $100 \mu$ l chloroform (Amresco LLC, USA) and centrifuged at $12,000 \times g$ at $4{ }^{\circ} \mathrm{C}$ for 15 mins. Obtained supernatants were mixed with $250 \mu \mathrm{l}$ isopropanol and centrifuged, and the RNA pellets so obtained were either rinsed with $70 \%$ ethyl alcohol and centrifuged at $7500 \times g$ at room temperature for $5 \mathrm{~min}$ or dissolved into $30 \mu \mathrm{l}$ of diethyl pyrocarbonate (DEPC)treated water. The levels of RNA were quantified by a Nanodrop 2000 (Thermo Fisher Scientific, Inc., USA). In order to conduct quantitative real-time polymerase chain reaction (qRT-PCR), complementary DNA (cDNA) synthesis was performed using a cDNA synthesis kit (TAKARA). Subsequently, cDNAs, SYBR green (TAKA RA), and adaptive primers were mixed and amplified in PCR (Bio-Rad, USA) to profile gene expression. Validated genes are listed in Table A1.

\section{Hematoxylin and eosin staining}

Paraffin block slides of pancreas tissues were deparaffinized, stained with Mayer's hematoxylin solution (DAKO, England) for $30 \mathrm{~s}$ and eosin $\mathrm{Y}$ solution (Sigma-Aldrich, USA) for $10 \mathrm{~s}$, rinsed 3 times with distilled water, and mounted using xylene-based DPX mounting solution. H\&E stained tissue slide images were captured by light microscopy and pancreatic islet sizes were calculated using the Image J software (NIH, USA).

\section{Data analysis}

The significances of intergroup differences were identified using the Kruskal-Wallis test. And, post-hoc comparisons were determined using Mann-Whitney $U$ test. The analysis was conducted using SPSS software, and results are expressed to means \pm SDs. Statistical analysis was admitted by $p$ values of $<0.05$. An asterisk indicates significantly different from the NFD/saline group and a number sign significantly different from the HFD/saline group.

\section{Results}

Effect of IOE on glucose tolerance in HFD mice

To determine whether IOE reduces elevated blood glucose level in HFD mice, we investigated glucose tolerance in HFD mice. We supplemented HFD mice feed with $\operatorname{IOE}(25,50$, or $75 \mathrm{mg} / \mathrm{kg}$, the HFD/IOE groups) for 4 weeks after mice had been fed HFD for 4 weeks. Intraperitoneal glucose tolerance test $(2 \mathrm{~g} / \mathrm{kg}$, IPGTT) was conducted at $30,60,90$, or 120 min after injection of glucose to investigate glucose tolerance. After 8 weeks, the HFD group gained more body weight compared with the NFD group. However, the HFD/IO $(25,50$, and 75 $\mathrm{mg} / \mathrm{kg}$ ) group showed a slightly decreased in body weight, but no significance compared with the HFD group. Body weight is shown in Figure 2A. As shown in Fig. 1a, HFD/saline controls (fed an HFD diet for 4 weeks and followed by saline for another 4 weeks) had lower glucose tolerance with higher blood glucose levels at each time after glucose injection than the NFD controls (fed a chow diet for 8 weeks). However, HFD/IOE groups (fed a HFD diet for 8 weeks and IOE at 25, 50, or $75 \mathrm{mg} / \mathrm{kg}$ for the latter 4 weeks) showed significant reductions in glucose levels at $120 \mathrm{~min}$ after glucose injection than were observed in the HFD group. AUC (area under the curve) levels of IPGTT were expressed to estimate the level of glucose tolerance impairment in each group. In line with the results shown in Fig. 1, the AUC of IPGTT in the HFD group was remarkably greater $(p$ $<0.001)$ than in the NFD group (Fig. 1b). HFD/IOE (25, 50 , or $75 \mathrm{mg} / \mathrm{kg}$ ) groups showed dose-dependent decreases in the AUC of IPGTT. The maintenance of fasting and $2 \mathrm{~h}$ glucose levels is a major therapeutic goal in diabetes (Ratner 2001). In Fig. 1c and d, both fasting and $2 \mathrm{~h}$ glucose levels in the HFD group were significantly higher than in the NFD group. However, fasting and $2 \mathrm{~h}$ glucose levels in the HFD/IOE 50 - and $75-\mathrm{mg} / \mathrm{kg}$ groups were significantly lower than in the HFD group. These results demonstrate that IOE can ameliorate glucose tolerance in HFD mice. Furthermore, we examined the improvement of IOE on glucose metabolism in the pancreas and muscle tissue of HFD mice in controlling blood glucose levels. 

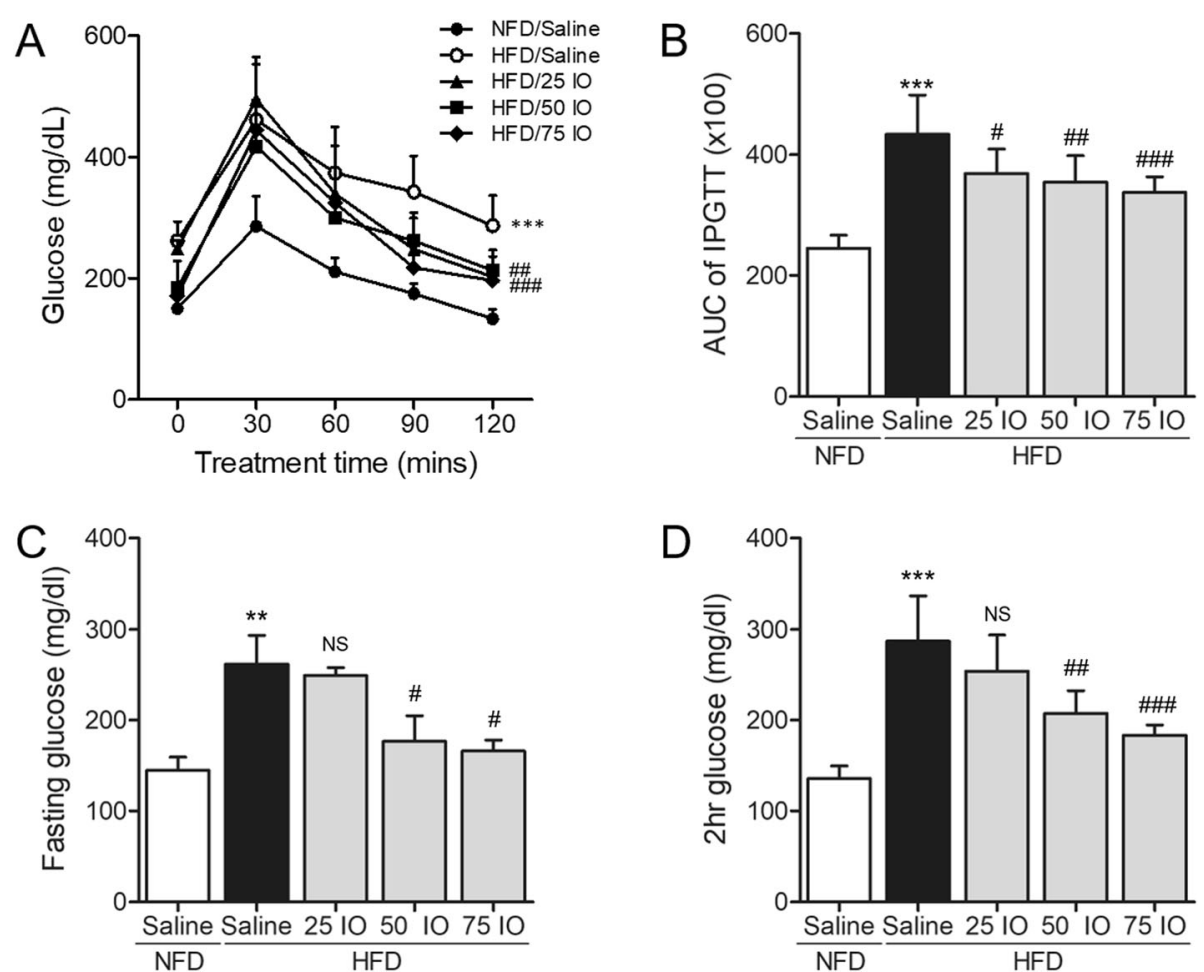

Fig. 1 Effect of IO on serum glucose levels in high-fat diet (HFD)-fed mice model. The mice receiving 45\% HFD for 8 weeks exhibit ameliorated glucose tolerance; however, IOE oral administration decreased glucose tolerance. $\mathbf{a}$, $\mathbf{b}$ Intraperitoneal glucose tolerance test (IPGTT) was performed and analyzed area under the curve (AUC) from the IPGTT in all mice groups. c Fasting and $\mathbf{d} 2 \mathrm{~h}$ glucose levels were in all mouse groups. Data are presented as mean \pm S.D. ${ }^{* *} p<0.01$ or ${ }^{* * *} p<0.001$ vs NFD/saline group; ${ }^{\#} p<0.05,{ }^{\# \#} p<0.01$, or ${ }^{* * *} p<0.001$ vs HFD/saline group. NS, not significant

\section{Effect of IOE on $\beta$-cell function in the pancreatic islets of HFD mice}

In order to investigate the effect of IOE on the morphologies and areas of the pancreatic islets of HFD mice, we conducted hematoxylin and eosin (H\&E) staining and immunohistochemistry (Matveyenko et al. 2009, Sun et al. 2016). The proliferating cell nuclear antigen (PCNA, a proliferation marker) was used to detect the proliferation of $\beta$ cells (Bringhenti et al. 2013). In order to identify the effect of IOE on the proliferation of $\beta$-cells in pancreatic islets, we measured PCNA intensities (Fig. 2a, b). PCNA intensities on $\beta$-cells in pancreatic islets of the HFD group were remarkably greater than in the NFD group, whereas PCNA intensities were dose-dependently decreased in the HFD/ IOE groups as compared to those of the HFD group. H\&E staining pancreatic islets were larger in HFD than in NFD mice (Fig. 2c, d), and that this increase in size was significantly and dose-dependently diminished in the HFD/IOE groups $(25,50$, or $75 \mathrm{mg} / \mathrm{kg})$. These data indicated that IOE can improve $\beta$-cell function in the pancreatic islet of HFD mice.

\section{Effect of IOE on pancreas dysfunction in HFD mice} HFD-induced diabetes is related to failure of $\beta$-cell function (Matveyenko et al. 2009, Cerf. 2006), and GLUT2 is essential for $\beta$-cell glucose sensing, which leads to glucose-induced insulin secretion (Cerf. 2006, Folli et al. 2011). In order to examine the effect of IOE on GLUT2 stimulation in pancreases of HFD mice, we evaluate the intensity of GLUT2 by immunofluorescence (Fig. 3a, b). The immunofluorescence intensity of GLUT2 in HFD mice was remarkably lower than in NFD mice $(p<0.05)$, and this reduction in immunofluorescence was slightly reduced in the HFD/IOE 20 - and $50-\mathrm{mg} / \mathrm{kg}$ groups, but significantly reduced in the $75-\mathrm{mg} / \mathrm{kg}$ group.

In addition, the GLUT2 transcription is controlled by pancreatic duodenal homeobox 1 (PDX1) and Hexokinase isoforms 1 (HK1) and 2 (HK2), which are also included in glucose sensing and glucose metabolism. We evaluated the effect of IOE on the mRNA levels of PDX1, HK1, and HK2 in pancreas tissues of HFD mice using qRT-PCR. mRNA levels of PDX1, HK1, and HK2 were remarkably decreased in HFD controls compared with NFD controls, which showed levels of GLUT2related transcription factors are impaired in HFD mice (Fig. 3c). However, these falls in PDX1 and HK1 mRNA levels were significantly prevented in the HFD/IOE 50and $75-\mathrm{mg} / \mathrm{kg}$ groups. Also, HK2 mRNA levels were significantly increased in the three HFD/IOE groups compared to those of HFD controls. These results showed 

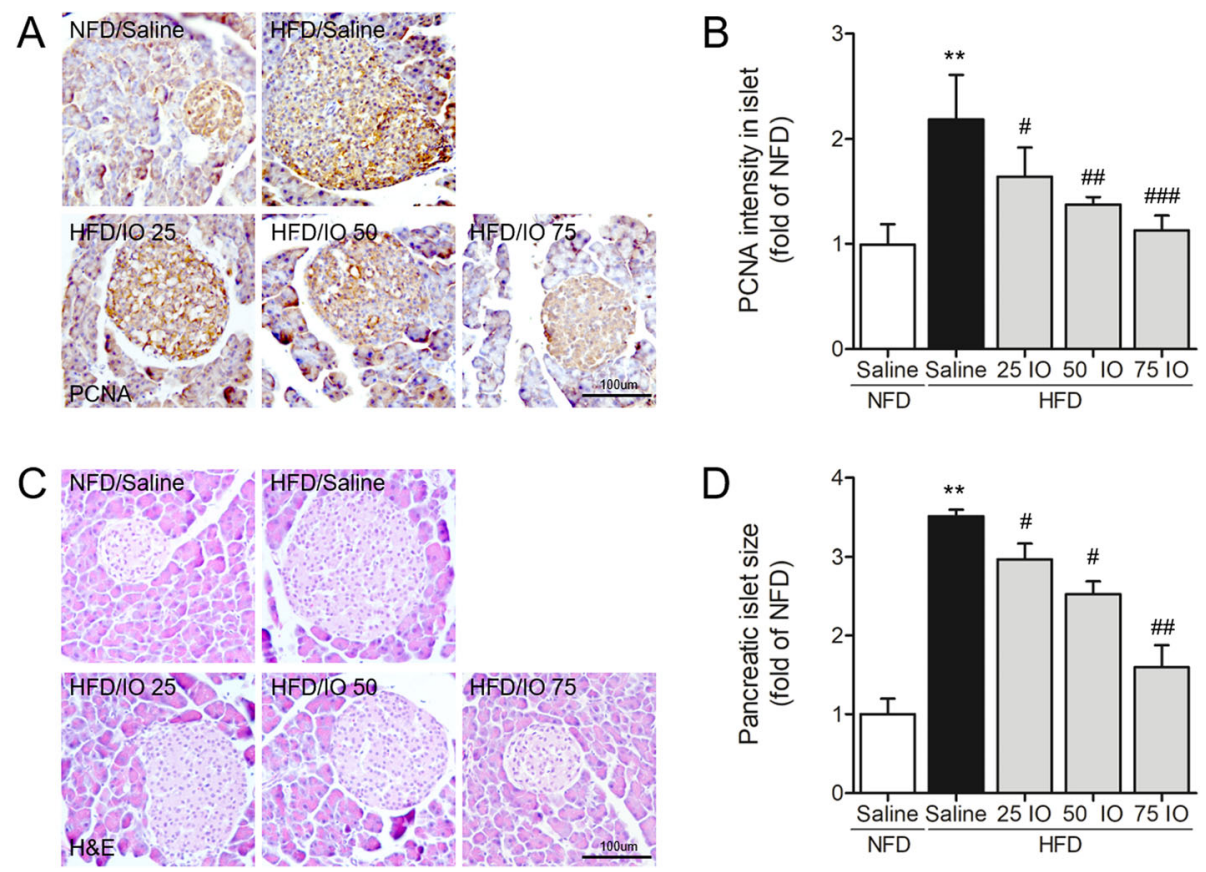

Fig. 2 Effects of IO on the morphologies and areas of pancreatic islets in high-fat diet (HFD)-fed mice model. a Proliferation marker of cell (proliferating cell nuclear antigen, PCNA) was evaluated by immunohistochemistry, and $\mathbf{b}$ quantitative graph shows the PCNA expression level on pancreatic islets from representative images. $\mathbf{c}$ Hematoxylin and eosin (H\&E)-stained pancreatic islets (round shape and pale color) and $\mathbf{d}$ the size of pancreatic islets were measured by the Image J software from representative images (scale bar $=100 \mu \mathrm{m}$ ). Data are presented as mean \pm S.D. ${ }^{* *} p<0.01$ vs NFD/saline group; ${ }^{\#} p<0.05,{ }^{\# \#} p<0.01$, or ${ }^{\# \# \#} p<0.001$ vs HFD/saline group
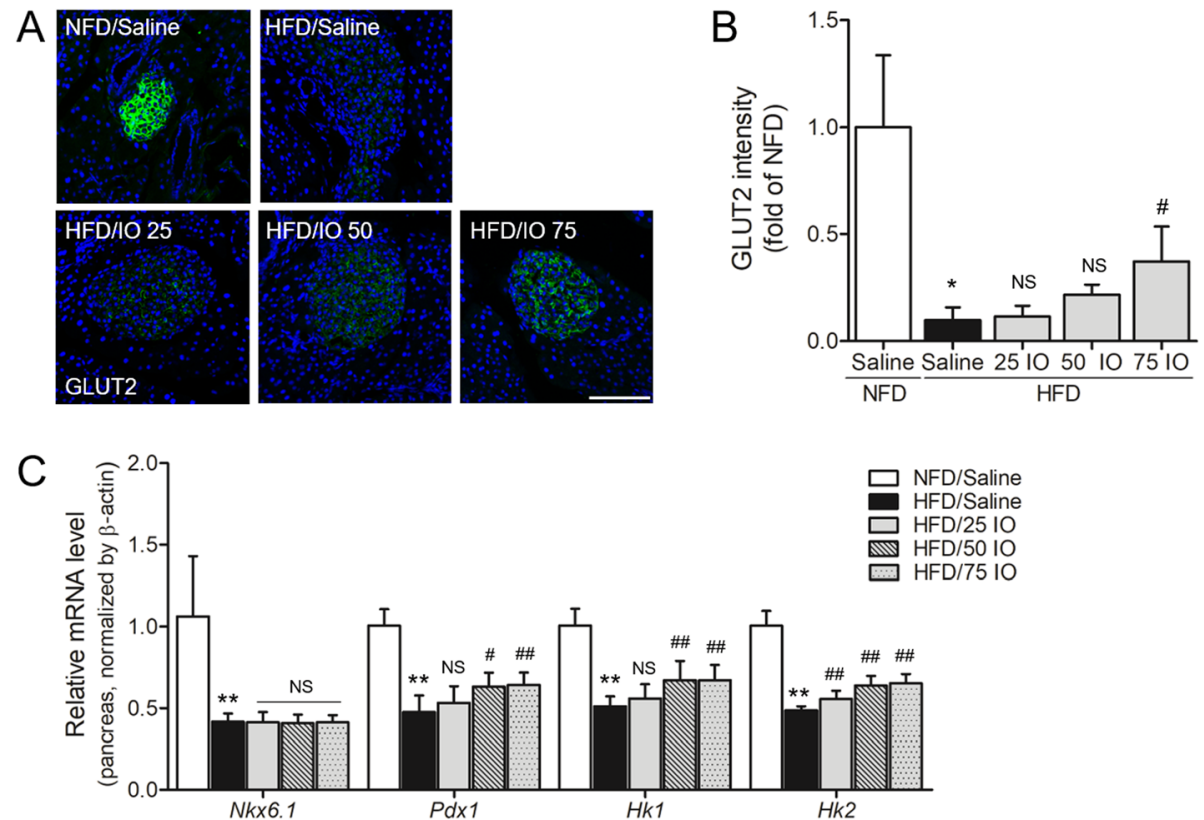

Fig. 3 Effects of IO on GLUT2 expression increase of pancreas tissues in high-fat diet (HFD)-fed mice model. a Confocal images show GLUT2 (green) expression and nuclei (blue; DAPI) were evaluated of pancreas tissues of all mice groups. b Quantitative graph shows the level of GLUT2 expression from representative images using the Zen 2012 software. c The mRNA levels of Pdx1, Hk1, and Hk2 were evaluated by qRT-PCR (scale $\mathrm{bar}=100 \mu \mathrm{m})$. Data are presented as mean \pm S.D. ${ }^{*} p<0.05$ or ${ }^{* *} p<0.01$ vs NFD/saline group; ${ }^{\#} p<0.05$ or ${ }^{\# \#} p<0.01$ vs HFD/saline group. NS, not significant 
that the increased GLUT2 and its related transcription factors PDX1, HK1, and HK2 by IOE can improve glucose metabolism in the pancreas.

\section{Effect of IOE on glucose metabolism in the skeletal muscle tissue of HFD mice}

GLUT4 levels and the levels of its related transcription factors were evaluated in the skeletal muscle of HFD mouse for glucose metabolism, which is the primary site of insulin-mediated GLUT4 translocation (Shepherd et al. 1998). The GLUT4 translocation into the membrane of the skeletal muscle in HFD mice was significantly decreased compared with NFD mice $(p<0.01$; Fig. 4a, b), and GLUT4 translocation was significantly greater in the HFD/IOE groups than in HFD groups ( $p$ $<0.05$ ). These observations suggest IOE can improve glucose metabolism in HFD mice by increasing translocation of GLUT4 into the membrane of the skeletal muscle.

Glucose metabolism in the skeletal muscle is achieved by activation of HK2, phosphoinositide-3-kinase (PI3$\mathrm{K}) / \mathrm{AKT}$, and AMP-activated protein kinase (AMPK) pathways (Fukumoto et al. 1988, Tsuchiya et al. 2010). We measured the mRNA level of AKT, AMPK, and HK2 in the skeletal muscle tissue of HFD mice by qRTPCR to assess the related level of GLUT4 and glucose metabolism by IOE. Consistent with our GLUT4 translocation results, qRT-PCR showed the mRNA level of AKT, AMAPK, and HK2 in the skeletal muscle were remarkably lower in HFD than in NFD controls (Fig. 3c), but that the mRNA levels of AKT and AMPK in the three HFD/IOE groups were significantly increased compared to those of the HFD controls $(p<0.01)$, and HK2 mRNA levels in HFD/IOE 50 - and $75-\mathrm{mg} / \mathrm{kg}$ groups were significantly higher than in HFD controls $(p<$ 0.01 ). These results demonstrate that IOE enhanced the transcription of GLUT4 and those of its related transcription factors AKT, AMPK, and HK2 in our mouse HFD model.

\section{Discussion}

Given that the underlying molecular mechanisms of type 2 diabetes with insulin resistance are accompanied by $\beta$ cell dysfunction, which is probable that the cross-talk between the pancreatic cells and skeletal muscle plays an important part. Thus, identification of a novel therapeutic agent that can control the glucose metabolism by enhancing the function of cells is key to restore the blood glucose homeostasis in type 2 diabetes patients.

Of note is that IOE has been announced to have various biological activities related to diabetes. For example, it has been reported to inhibit $\alpha$-glucosidase, improve glucose tolerance, upregulate levels of hepatic glucose metabolites, and reduce insulin resistance in $\mathrm{db} / \mathrm{db}$ mice
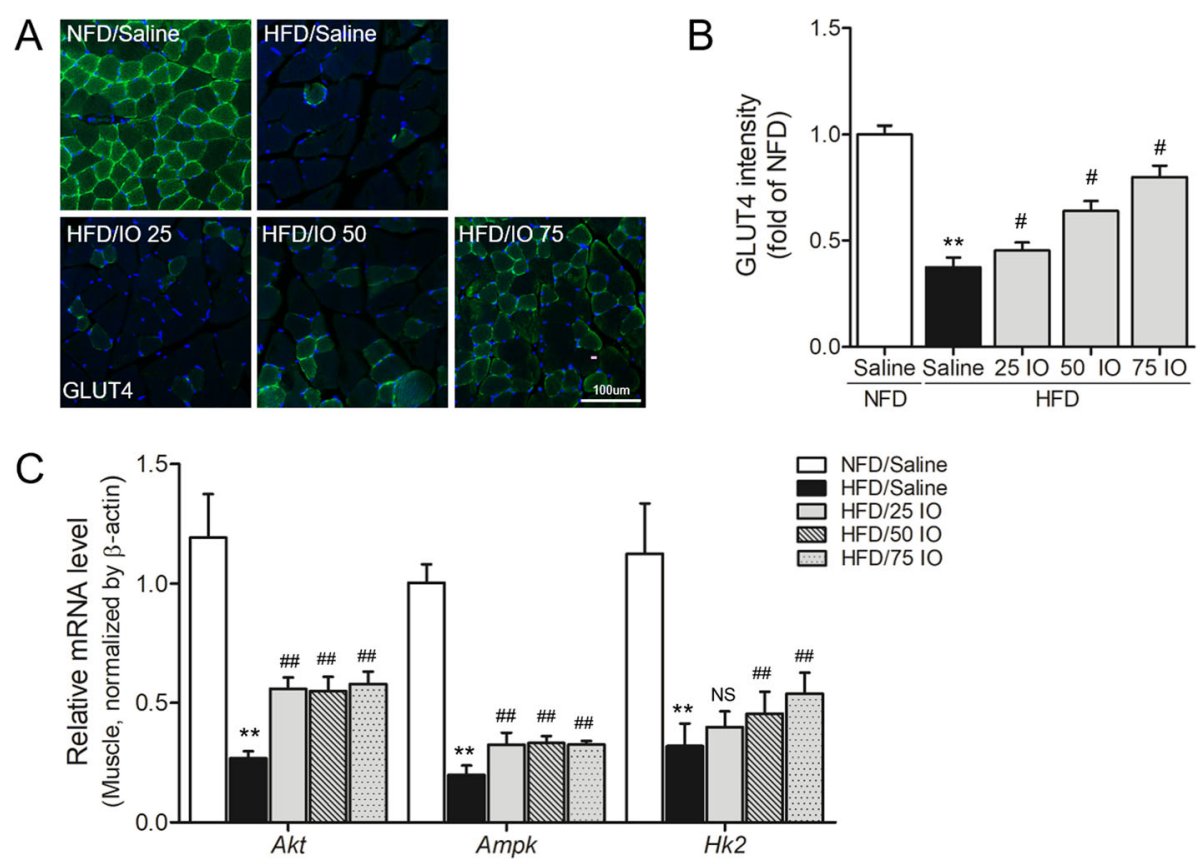

Fig. 4 Effects of IO on GLUT4 expression increase of skeletal muscle tissues in high-fat diet (HFD)-fed mice model. a Confocal images show GLUT4 (green) expression and nuclei (blue; DAPI) were evaluated of skeletal muscle tissue of all mice groups. b Quantitative graph shows the level of GLUT4 expression from representative images using Zen 2012 software (scale bar = $100 \mathrm{um}$ ). c The mRNA levels of Akt, Ampk, and Hk2 were evaluated by qRT-PCR. Data are presented as mean \pm S.D. ${ }^{* *} p<0.01$ vs NFD/saline group; ${ }^{\#} p<0.05$ or ${ }^{\# \#} p<0.01$ vs HFD/saline group. NS, not significant 
(Min et al. 2011, Ryu et al. 2018, Heo et al. 2009). However, the effect of IOE on functions of glucose transport in the pancreases and skeletal muscle tissues is yet to be assessed in HFD mice that have been fed with an imbalanced diet to induce mild hyperglycemia, a condition that may resemble the pre-diabetic state in humans. Therefore, we firstly confirmed that the decreased glucose transporter function in the pancreases and skeletal muscle tissues of HFD mice fed for 4 weeks was significantly ameliorated alongside improved glucose metabolism upon IOE administration for another 4 weeks.

The severe glucose intolerance in HFD mice with decreased insulin sensitivity may decelerate $\beta$-cell function in pancreatic islets, leading to excessive $\beta$-cell proliferation and increased pancreatic islet size (Matveyenko et al. 2009, Carey et al. 1996, Butler et al. 2003). Hull et al. have shown that rodents fed with an HFD to induce insulin resistance develop increased pancreatic islet size due to hyperplasia rather than hypertrophy of $\beta$-cells (Hull et al. 2005). We herein observed that the decelerated $\beta$-cell function in the pancreatic islet of HFD mice was noticeably improved by IOE administration, probably because of the restoration of the GLUT2 level. The major glucose transporter GLUT2 in hypertrophied pancreatic islets is associated with glucose sensing to stimulate insulin secretion. The mechanism of the improvement of the pancreas function by IOE through GLUT2 upregulation in the islets is linked with the regulation of PDX1, HK1, and $H K 2$ mRNA levels, enabling acquisition of glucoseresponsive insulin secretion (Frantz et al. 2013). PDX1 mutant $\beta$-cells have been shown to activate the isletspecific GLUT2 and amyloid polypeptide, and these two factors have been shown to be low in diabetic mice and patients (Nicolino et al. 2010, Suzuki et al. 2003, Waeber et al. 1996). HK1 and HK2 play key roles in glucose sensing by catalyzing glycolysis through which glucose is phosphorylated to produce glycos-6-phosphate (Hashimoto et al. 2005). Epstein et al. have reported that the elevated hexokinase activity of both HK1 and HK2 in $\beta$-cells can reduce the blood glucose level in diabetes patients (Epstein et al. 1992).

The skeletal muscle of HFD mice is known to be defective in the membrane translocation of GLUT4 alongside impaired glucose metabolism and reduced insulinstimulated glucose transport (Fukumoto et al. 1988, Tremblay et al. 2001, Savage et al. 2007). Increased GLUT4 translocation by IOE probably facilitates glucose uptake of the skeletal muscle in HFD mice, activating the PI3K/AKT and AMPK pathways, thereby regulating the glucose metabolism, including glycogen synthesis, gluconeogenesis, and glucose transport as well as the energy expenditure (Schultze et al. 2012). Consistent with these findings, we found that the mRNA level of $H K 2$, which promotes glucose transport and utilization, was also upregulated in HFD mice fed with IOE (Fukumoto et al. 1988).

In this study, our findings are summarized as follows: (1) IOE supplementation ameliorated blood glucose intolerance, (2) improved glucose metabolism in the pancreas, and (3) enhanced glucose transporters in the skeletal muscle. Additionally, our results suggest that the euglycemic effects of IOE in HFD mice are because of the stimulation of the glucose metabolism.

\section{Conclusion}

This study shows IOE (an ethanolic extract of Ishige okamurae) had euglycemic effects in our HFD-induced mice model of diabetes and that these effected were associated with improved glucose metabolism in the pancreas and skeletal muscle and lower blood glucose levels. We suggest that IOE is considered a potential starting point for developing the therapeutic or functional foods targeting the alleviation of diabetes.

\section{Supplementary information}

Supplementary information accompanies this paper at https://doi.org/10. 1186/s41240-020-00168-5.

Additional file 1: Figure A1. HPLC chromatogram of DPHC from IOE

Additional file 2: Table A1. List of $q R T-P C R$ primer sequences

Additional file 3: Figure A2. Effect of $1 O$ on body weight in high fat diet (HFD)-fed mice model. Data are presented as mean \pm S.D $(n=3$ for each group). ${ }^{* * *} p<0.01$ vs NFD/saline group. NS, not significant.

\section{Abbreviations}

AMPK: AMP-activated protein kinase; cDNA: Complementary DNA; DEPC: Diethyl pyrocarbonate; DPHC: Diphlorethohydroxycarmalol; ESI: Electrospray ionization; GLUT2: Glucose transporter 2; GLUT4: Glucose transporter 4; H\&E: Hematoxylin and eosin; HFD: High-fat diet; HK1: Hexokinase isoforms 1; HK2: Hexokinase isoforms 2; IO: Ishige okamurae; IOE: Ethanolic IO extract; IPGTT: Intraperioneal glucose tolerance testing; PCNA: Proliferating cell nuclear antigen; PDX1: Pancreatic duodenal homeobox 1; PI3-K: Phosphoinositide-3-kinase; qRT-PCR: Quantitative realtime polymerase chain reaction; Q-TOF LC-MS/MS: Quadrupole time-of-flight lipid chromatography-mass spectrometry

\section{Acknowledgements}

This research was a part of the project titled "Development of functional food products with natural materials derived from marine resources (no. 20170285)," funded by the Ministry of Oceans and Fisheries, Korea. The IOE in this study was kindly provided by Dong-Min Chung in Shinwoo Co. Ltd., Republic of Korea.

\section{Authors' contributions}

H.-W.Y.: Provided the substance and draft preparation. M.S. and S.O.: Data assembly and interpretation. S.O. and J.C.: Formal analysis and data collection. Y.-J.J. and K.B.: Study conceptualization and methodology. K.B. and B.R.: Supervision and provision of funding acquisition. The authors read and approved the final manuscript.

Availability of data and materials

The data used to support the findings of this study are included within the manuscript. 


\section{Ethics approval and consent to participate}

Animal experiments were performed according to the guidelines signed by the Animal Care and Use Committee of Gachon University (IACUC; LCDI2018-0112).

\section{Competing interests}

The authors declare that they have no competing interests.

\section{Author details}

'Department of Marine Life Science, School of Marine Biomedical Sciences, Jeju National University, 1 Ara 1-dong, Jejudaehak-ro, Jeju 63243, Republic of Korea. ${ }^{2}$ Department of Anatomy \& Cell Biology, Gachon University College of Medicine, Incheon 21565, Republic of Korea. ${ }^{3}$ Functional Cellular Networks Laboratory, Lee Gil Ya Cancer and Diabetes Institute, Gachon University, Incheon 21999, Republic of Korea. ${ }^{4}$ Marine Science Institute, Jeju National University, Jeju 63333, Republic of Korea.

\section{Received: 21 May 2020 Accepted: 24 July 2020}

\section{Published online: 09 September 2020}

\section{References}

Bell GI, Polonsky KS. Diabetes mellitus and genetically programmed defects in $\beta$ cell function. Nature. 2001;414:788.

Bonny C, Roduit R, Gremlich S, Nicod P, Thorens B, Waeber G. The loss of GLUT2 expression in the pancreatic $\beta$-cells of diabetic $\mathrm{db} / \mathrm{db}$ mice is associated with an impaired DNA-binding activity of islet-specific trans-acting factors. Mol Cell Endocrinol. 1997;135:59-65.

Bringhenti I, Moraes-Teixeira JA, Cunha MR, Ornellas F, Mandarim-de-Lacerda CA, Aguila MB. Maternal obesity during the preconception and early life periods alters pancreatic development in early and adult life in male mouse offspring. PLOS ONE. 2013;8:e55711.

Butler AE, Janson J, Bonner-Weir S, Ritzel R, Rizza RA, Butler PC. $\beta$-cell deficit and increased $\beta$-cell apoptosis in humans with type 2 diabetes. Diabetes. 2003;52: 102-10.

Carey DG, Jenkins AB, Campbell LV, Freund J, Chisholm DJ. Abdominal fat and insulin resistance in normal and overweight women: direct measurements reveal a strong relationship in subjects at both low and high risk of NIDDM. Diabetes. 1996:45:633-8.

Cerf ME. High fat diet modulation of glucose sensing in the beta-cell. Med Sci Monit. 2006;13:RA12-7.

Chang L, Chiang S-H, Saltiel AR. Insulin signaling and the regulation of glucose transport. Mol Med. 2004;10:65.

Epstein PN, Boschero AC, Atwater I, Cai X, Overbeek PA. Expression of yeast hexokinase in pancreatic beta cells of transgenic mice reduces blood glucose, enhances insulin secretion, and decreases diabetes. Proc Natl Acad Sci USA. 1992:89:12038-42.

Folli F, Okada T, Perego C, Gunton J, Liew CW, Akiyama M, D'Amico A, La Rosa S, Placidi C, Lupi R. Altered insulin receptor signalling and $\beta$-cell cycle dynamics in type 2 diabetes mellitus. PLOS ONE. 2011;6:e28050.

Frantz EDC, Crespo-Mascarenhas C, Barreto-Vianna ARC, Aguila MB, Mandarim-deLacerda CA. Renin-angiotensin system blockers protect pancreatic islets against diet-induced obesity and insulin resistance in mice. PLOS ONE. 2013; 8:e67192.

Fukumoto H, Seino S, Imura H, Seino Y, Bell Gl. Characterization and expression of human HepG2/erythrocyte glucose-transporter gene. Diabetes. 1988;37: 657-61.

Giugliano D, Ceriello A, Esposito K. Glucose metabolism and hyperglycemia. Am J Clin Nutr. 2008:87:217S-22S.

Guilherme A, Virbasius JV, Puri V, Czech MP. Adipocyte dysfunctions linking obesity to insulin resistance and type 2 diabetes. Nat Rev Mol Cell Biol. 2008; 9:367.

Hamza N, Berke B, Cheze C, Agli A-N, Robinson P, Gin H, Moore N. Prevention of type 2 diabetes induced by high fat diet in the C57BL/6 J mouse by two medicinal plants used in traditional treatment of diabetes in the east of Algeria. J Ethnopharmacol. 2010;128:513-8

Hashimoto N, Kido Y, Uchida T, Matsuda T, Suzuki K, Inoue H, Matsumoto M, Ogawa W, Maeda S, Fujihara $H$. PKC $\lambda$ regulates glucose-induced insulin secretion through modulation of gene expression in pancreatic $\beta$ cells. J Clin Investig. 2005;115:138-45.

Heo S-J, Hwang J-Y, Choi J-I, Han J-S, Kim H-J, Jeon Y-J. Diphlorethohydroxycarmalol isolated from Ishige okamurae, a brown algae, a potent a-glucosidase and a-amylase inhibitor, alleviates postprandial hyperglycemia in diabetic mice. Eur J Pharmacol. 2009;615:252-6.

Herman MA, Kahn BB. Glucose transport and sensing in the maintenance of glucose homeostasis and metabolic harmony. J Clin Investig. 2006;116:176775.

Honors MA, Hargrave SL, Kinzig KP. Glucose tolerance in response to a high-fat diet is improved by a high-protein diet. Obesity. 2012;20:1859-65.

Hull R, Kodama K, Utzschneider K, Carr D, Prigeon R, Kahn S. Dietary-fat-induced obesity in mice results in beta cell hyperplasia but not increased insulin release: evidence for specificity of impaired beta cell adaptation. Diabetologia. 2005;48:1350-8.

Kiuru P, MV DA, Muller CD, Tammela P, Vuorela H, Yli-Kauhaluoma J. Exploring marine resources for bioactive compounds. Planta Med. 2014;80:1234-46.

Konrad D, Bilan PJ, Nawaz Z, Sweeney G, Niu W, Liu Z, Antonescu CN, Rudich A, Klip A. Need for GLUT4 activation to reach maximum effect of insulinmediated glucose uptake in brown adipocytes isolated from GLUT4mycexpressing mice. Diabetes. 2002:51:2719-26.

Lee S-H, Park M-H, Heo S-J, Kang S-M, Ko S-C, Han J-S, Jeon Y-J. Dieckol isolated from Ecklonia cava inhibits a-glucosidase and a-amylase in vitro and alleviates postprandial hyperglycemia in streptozotocin-induced diabetic mice. Food Chem Toxicol. 2010:48:2633-7.

Matveyenko AV, Gurlo T, Daval M, Butler AE, Butler PC. Successful versus failed adaptation to high-fat diet-induced insulin resistance: the role of IAPP_ induced $\beta$-cell endoplasmic reticulum stress. Diabetes. 2009;58:906-16.

Min K-H, Kim H-J, Jeon Y-J, Han J-S. Ishige okamurae ameliorates hyperglycemia and insulin resistance in C57BL/KsJ-db/db mice. Diabetes Res Clin Pract. 2011;93:70-6.

Murugan AC, Karim MR, Yusoff MBM, Tan SH, Asras MFBF, Rashid SS. New insights into seaweed polyphenols on glucose homeostasis. Pharm Biol. 2015;53: 1087-97.

Nicolino M, Claiborn KC, Senée V, Boland A, Stoffers DA, Julier C. A novel hypomorphic PDX1 mutation responsible for permanent neonatal diabetes with subclinical exocrine deficiency. Diabetes. 2010;59:733-40.

Nishiumi S, Bessyo H, Kubo M, Aoki Y, Tanaka A, Yoshida K-I, Ashida H. Green and black tea suppress hyperglycemia and insulin resistance by retaining the expression of glucose transporter 4 in muscle of high-fat diet-fed C57BL/6 J mice. J Agric Food Chem. 2010;58:12916-23.

Ratner RE. Controlling postprandial hyperglycemia. Am J Cardiol. 2001;88:26-31.

Riant E, Waget A, Cogo H, Arnal J-F, Burcelin R, Gourdy P. Estrogens protect against high-fat diet-induced insulin resistance and glucose intolerance in mice. Endocrinology. 2009;150:2109-17.

Rines AK, Sharabi K, Tavares CD, Puigserver P. Targeting hepatic glucose metabolism in the treatment of type 2 diabetes. Nat Rev Drug Discov. 2016; 15:786.

Ryu B, Jiang Y, Kim H-S, Hyun J-M, Lim S-B, Li Y, Jeon Y-J. Ishophloroglucin A, a novel phlorotannin for standardizing the anti-a-glucosidase activity of Ishige okamurae. Mar Drugs. 2018:16:436.

Sanjeewa KA, Lee WW, Kim J-I, Jeon Y-J. Exploiting biological activities of brown seaweed Ishige okamurae Yendo for potential industrial applications: a review. J Appl Phycol. 2017;29:3109-19.

Savage DB, Petersen KF, Shulman GI. Disordered lipid metabolism and the pathogenesis of insulin resistance. Physiol Rev. 2007;87:507-20.

Schultze SM, Hemmings BA, Niessen M, Tschopp O. PI3K/AKT, MAPK and AMPK signalling: protein kinases in glucose homeostasis. Expet Rev Mol Med. 2012;14.

Shan W-F, B-q C, Zhu S-j, Jiang L, Zhou Y-F. Effects of GLUT4 expression on insulin resistance in patients with advanced liver cirrhosis. J Zhejiang Univ Sci B. 2011:12:677

Sharifuddin Y, Chin Y-X, Lim P-E, Phang S-M. Potential bioactive compounds from seaweed for diabetes management. Mar Drugs. 2015;13:5447-91.

Shepherd PR, Withers DJ, Siddle K. Phosphoinositide 3-kinase: the key switch mechanism in insulin signalling. Biochem J. 1998:333:471-90.

Sun Q, Nie S, Wang L, Yang F, Meng Z, Xiao H, Xiang B, Li X, Fu X, Wang S. Factors that affect pancreatic islet cell autophagy in adult rats: evaluation of a calorie-restricted diet and a high-fat diet. PLOS ONE. 2016;11:e0151104.

Suzuki R, Tobe K, Terauchi Y, Komeda K, Kubota N, Eto K, Yamauchi T, Azuma K, Kaneto $\mathrm{H}$, Taguchi T. Pdx1 expression in Irs2-deficient mouse $\beta$-cells is regulated in a strain-dependent manner. J Biol Chem. 2003;278:43691-8.

Tremblay F, Lavigne C, Jacques H, Marette A. Defective insulin-induced GLUT4 translocation in skeletal muscle of high fat-fed rats is associated with alterations in both Akt/protein kinase B and atypical protein kinase $C(C / \lambda)$ activities. Diabetes. 2001;50:1901-10. 
Tsuchiya Y, Hatakeyama H, Emoto N, Wagatsuma F, Matsushita S, Kanzaki M. Palmitate-induced down-regulation of sortilin and impaired GLUT4 trafficking in C2C12 myotubes. J Biol Chem. 2010;285:34371-81.

Tsuneki H, Ishizuka M, Terasawa M, Wu J-B, Sasaoka T, Kimura I. Effect of green tea on blood glucose levels and serum proteomic patterns in diabetic (db/ db) mice and on glucose metabolism in healthy humans. BMC Pharmacol. 2004;:18.

Waeber G, Thompson N, Nicod P, Bonny C. Transcriptional activation of the GLUT2 gene by the IPF-1/STF-1/IDX-1 homeobox factor. Mol Endocrinol. 1996;10:1327-34.

Wiegand S, Dannemann A, Krude H, Grüters A. Impaired glucose tolerance and type 2 diabetes mellitus: a new field for pediatrics in Europe. Int J Obes. 2005;29:5136

Yamashita Y, Wang L, Tinshun Z, Nakamura T, Ashida H. Fermented tea improves glucose intolerance in mice by enhancing translocation of glucose transporter 4 in skeletal muscle. J Agric Food Chem. 2012;60:11366-71. Yang H-W, Son M, Choi J, Oh S, Jeon Y-J, Byun K, Ryu B. Effect of ishophloroglucin A, a component of Ishige okamurae, on glucose homeostasis in the pancreas and muscle of high fat diet-fed mice. Mar Drugs. 2019;17:608

\section{Publisher's Note}

Springer Nature remains neutral with regard to jurisdictional claims in published maps and institutional affiliations.

Ready to submit your research? Choose BMC and benefit from:

- fast, convenient online submission

- thorough peer review by experienced researchers in your field

- rapid publication on acceptance

- support for research data, including large and complex data types

- gold Open Access which fosters wider collaboration and increased citations

- maximum visibility for your research: over $100 \mathrm{M}$ website views per year

At BMC, research is always in progress.

Learn more biomedcentral.com/submissions 